\title{
Marine and freshwater micropearls: biomineralization producing strontium-rich amorphous calcium carbonate inclusions is widespread in the genus Tetraselmis (Chlorophyta)
}

\section{Supplementary Materials}

Agathe Martignier ${ }^{1}$, Montserrat Filella ${ }^{2}$, Kilian Pollok ${ }^{3}$, Michael Melkonian ${ }^{4}$, Michael Bensimon ${ }^{5}$, François Barja $^{6}$, Falko Langenhorst ${ }^{3}$, Jean-Michel Jaquet ${ }^{1}$, Daniel Ariztegui ${ }^{1}$

${ }^{1}$ Department of Earth Sciences, University of Geneva, Geneva, 1205, Switzerland

${ }^{2}$ Department F.-A. Forel, University of Geneva, Geneva, 1205, Switzerland

${ }^{3}$ Institute of Geosciences, Friedrich Schiller University Jena, Jena, 07745, Germany

${ }^{4}$ Botany Department, Cologne Biocenter, University of Cologne, Cologne, 50674, Germany

${ }^{5}$ EPFL ENAC IIE GR-CEL IsoTraceLab, EPFL, Lausanne, 1015 Switzerland

15

${ }^{6}$ Microbiology Unit, University of Geneva, Geneva, 1205, Switzerland

Correspondence to: Agathe Martignier (agathe.martignier@unige.ch) 


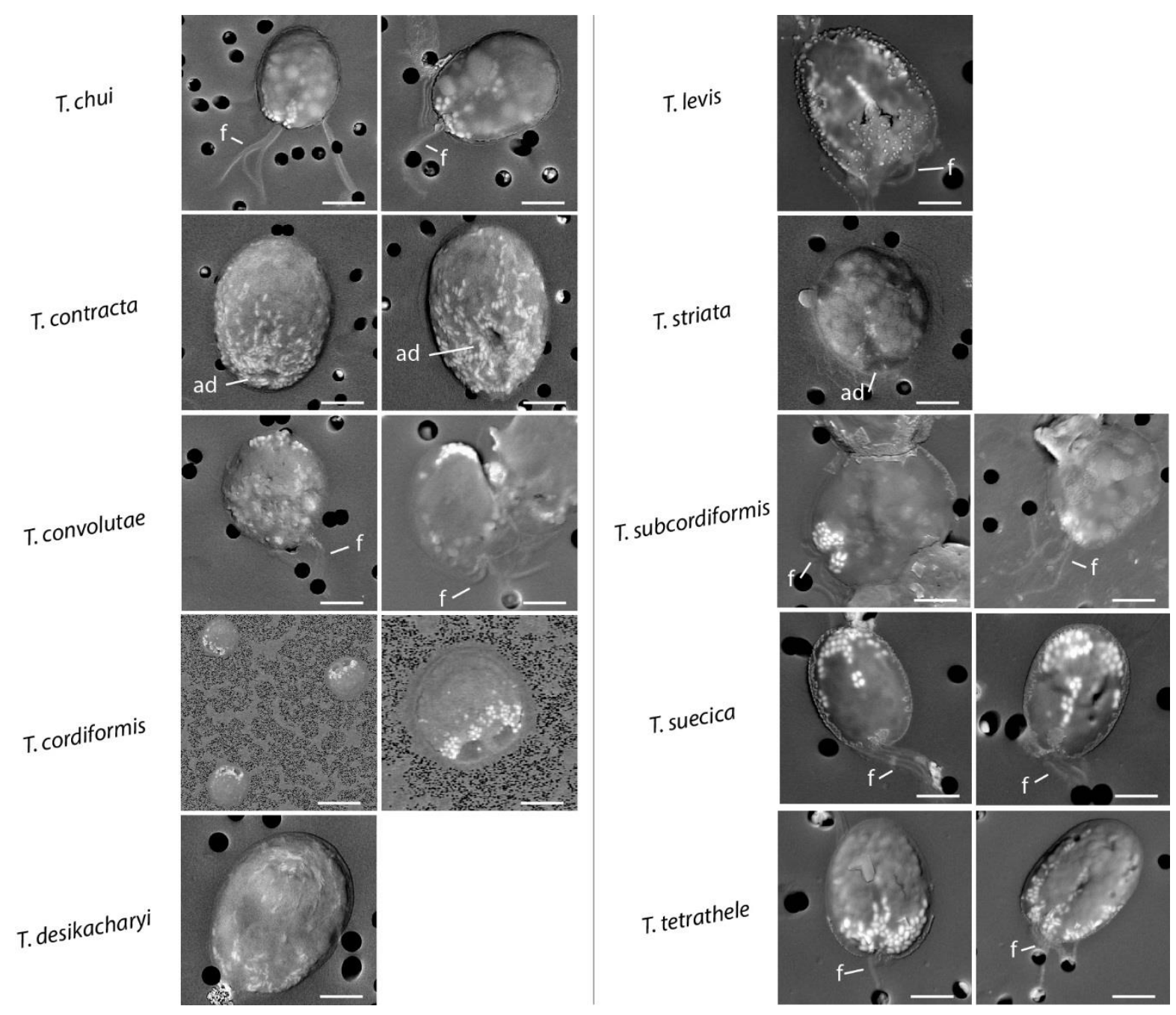

Figure S1: SEM images providing an overview of the micropearl location in Tetraselmis species.

Backscattered electron images of dried samples. The micropearls appear in white or light grey against the darker organic matter. The larger and slightly darker inclusions are polyphosphate (observed here in T. chui, T. convolutae, T. striata, T. subcordiformis). Pores of the filters are visible as black circles in the background ( $0.2 / 1$ or 2 micrometers of diameter). The location of the micropearls is linked to the observation of flagella (f) or of the apical depression (ad). In T. cordiformis, the two contractile vacuoles are clearly visible and are located at the apical side of the cell. Finally, the orientation of $T$. desikacharyi stays completely uncertain, although similar observations in $T$. convolutae seem to indicate that the iron oxide minerals (in white) are formed around the (missing) flagella. Scale bars: $5 \mu \mathrm{m}$. 


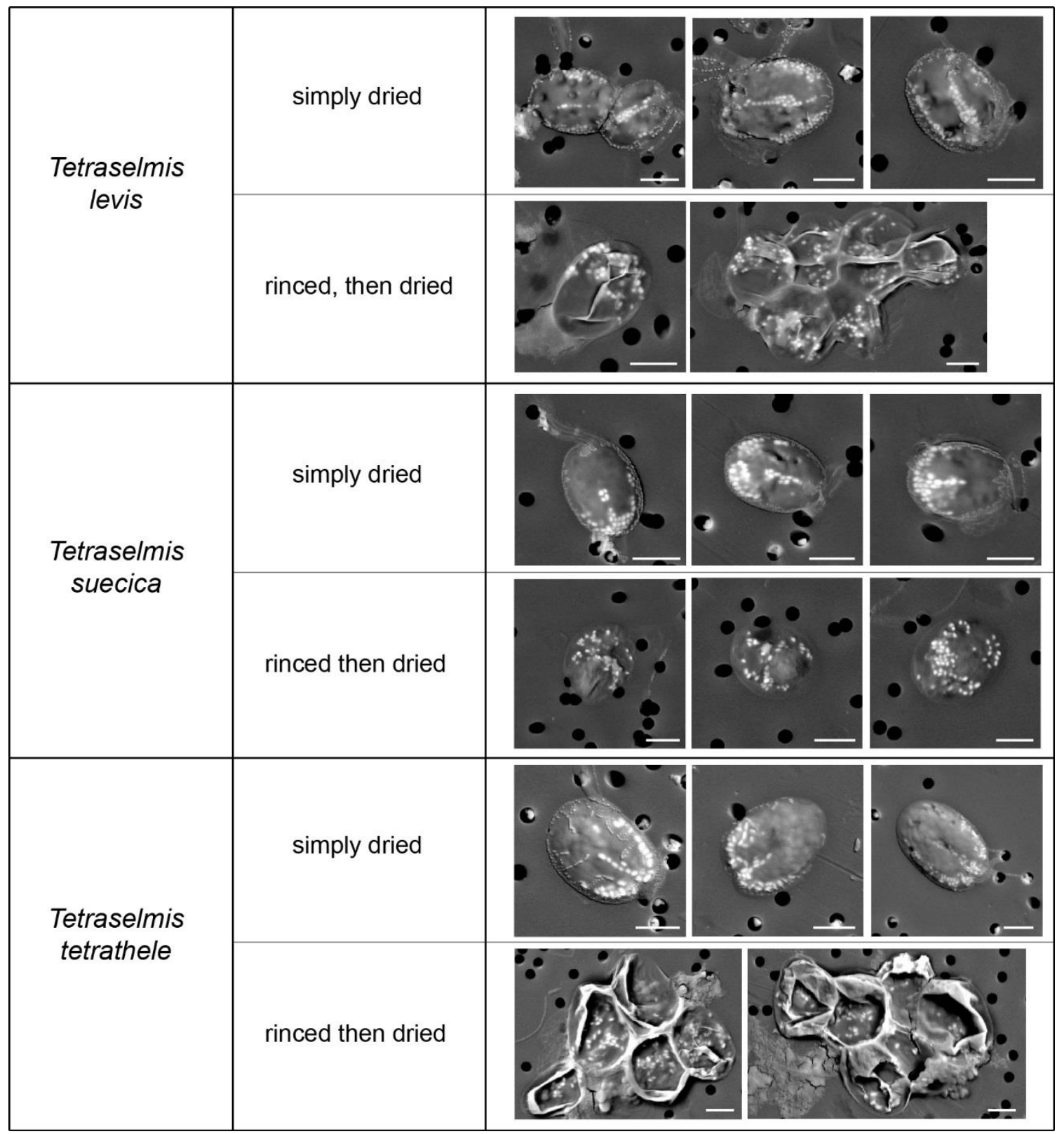

Figure S2: Micropearl distribution inside the cell disrupted by MilliQ water rinsing.

SEM backscattered electron images of dried samples. The micropearls appear in white or light grey against the darker organic matter. Each culture was sampled at the same time, but prepared in two different ways: either simply dried on a filter, either rinsed shortly with MilliQ water and then dried on a filter. The micropearls' distribution inside the cell is not preserved when the sample is rinsed. Scale bars: $5 \mu \mathrm{m}$. 


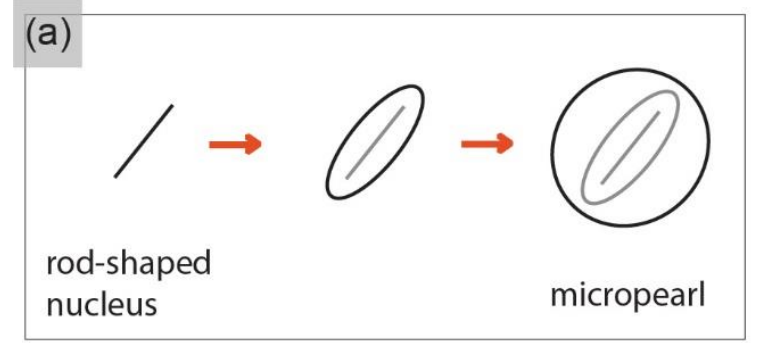

(b)

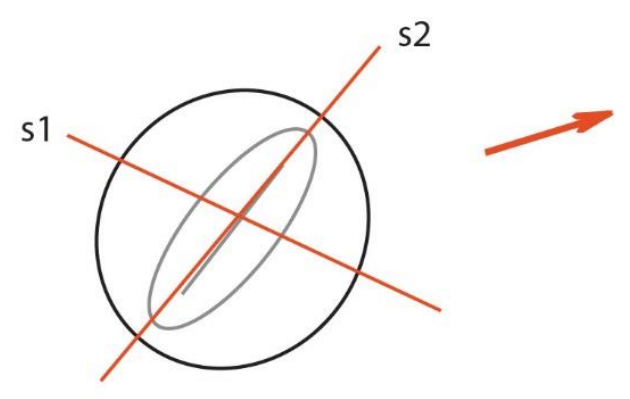

s1
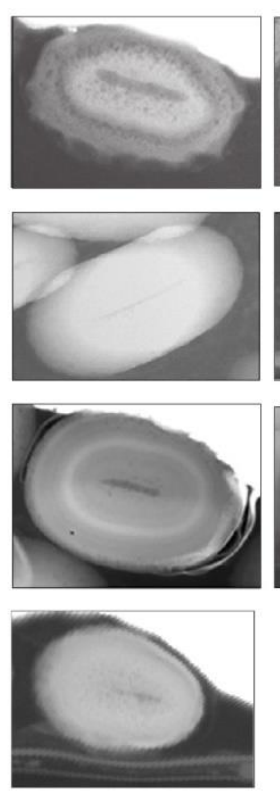

s2

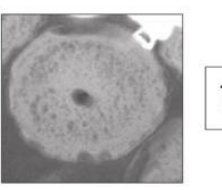

T. chui

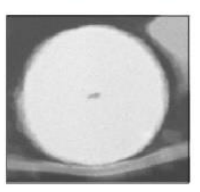

T. contracta

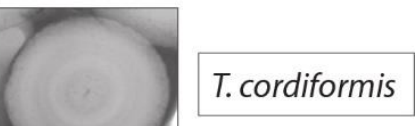

T. suecica

Figure S3: Nucleus shape interpretation for micropearls formed by Tetraselmis species.

Cells from algal cultures except T.cf cordiformis, which was sampled in Lake Geneva (dried samples). (a) Diagram of a possible formation process starting from a rod-shaped nucleus. (b) TEM HAADF images of FIB-cut sections in micropearls formed by Tetraselmis species, corresponding to the cross-sections located on the left hand-side drawing. The micropearls measure between 0.7 (T. chui) to $1.2 \mu \mathrm{m}$ (T. contracta) in length. 

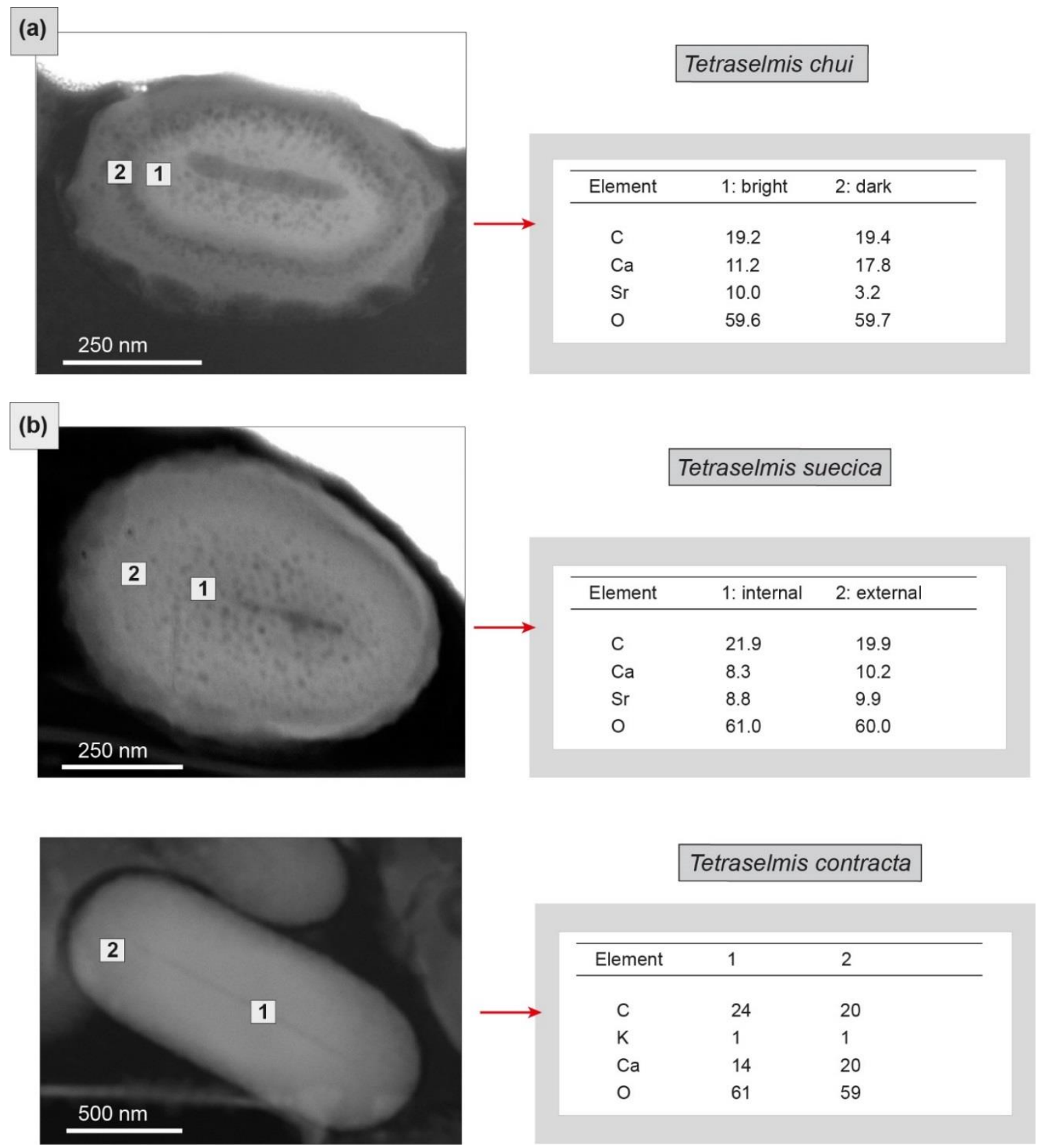

Figure S4: TEM-EDXS analyses of T. contracta, T. chui and T. suecica micropearls composition.

STEM - HAADF image. The location of the EDXS analyses (right hand-side table) is indicated by the corresponding numbers. Results are normalized to 100 at $\%$. O is calculated stoichiometrically based on the cation concentrations. Notice the low but

significant presence of $\mathrm{K}$ in the micropearl composition of $T$. contracta. However its analysis $\mathrm{n}^{\circ} 1$ does not fulfil carbonate stoichiometry, which may be due to the excess $\mathrm{C}$ from organic matter. Note that the calculation mode for the analyses presented in this figure differ from those presented in the rest of the manuscript, as $\mathrm{C}$ and $\mathrm{O}$ are included in the composition. 

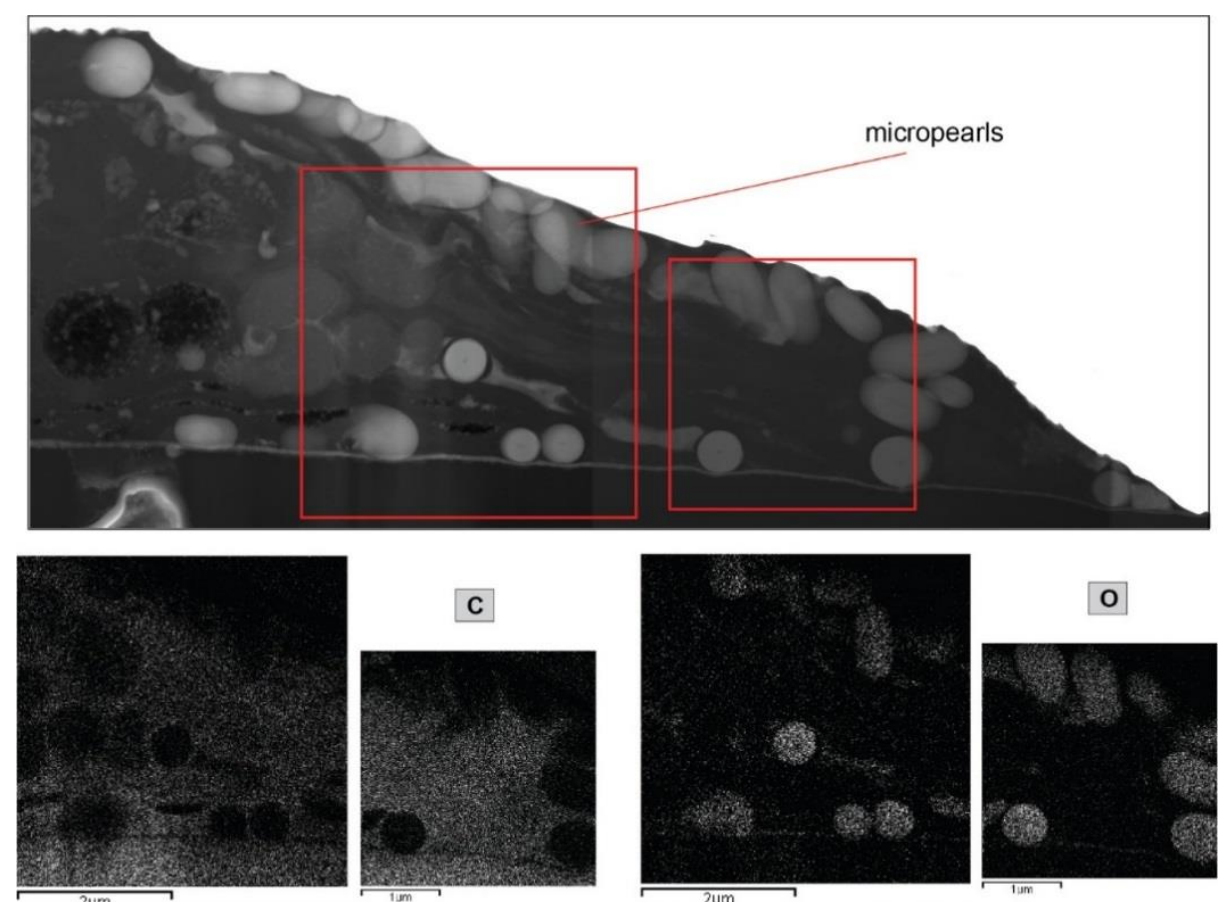

C
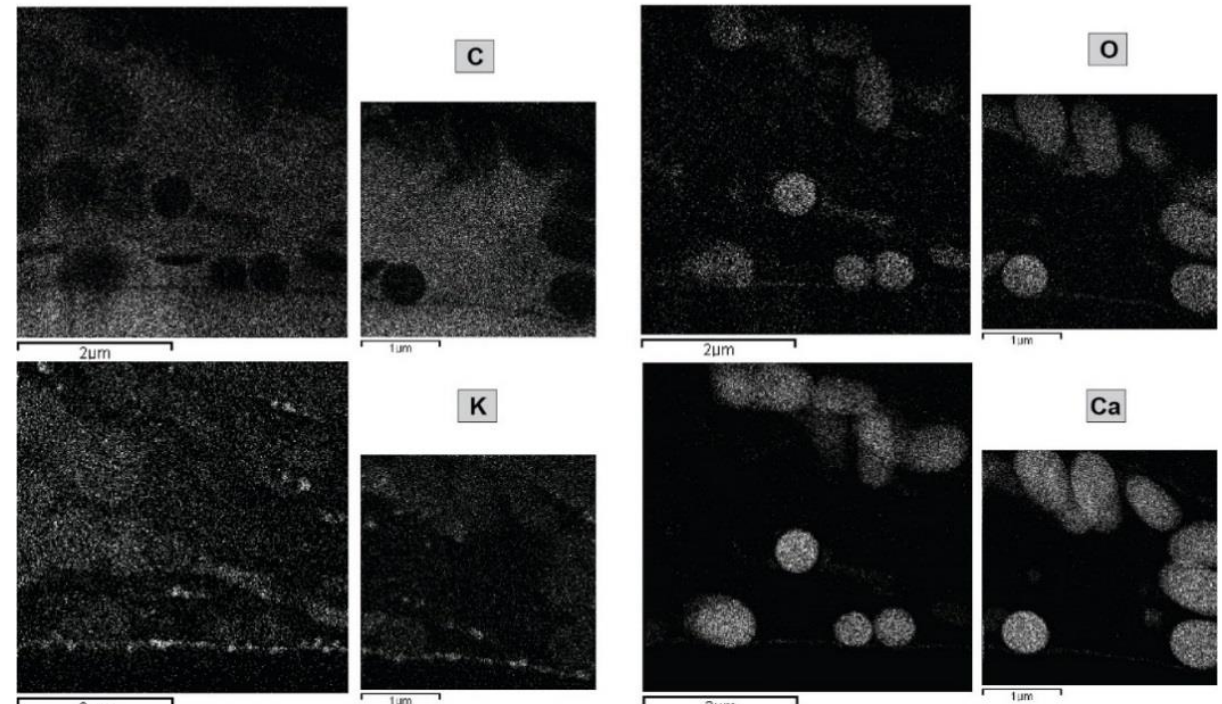

$\mathbf{K}$
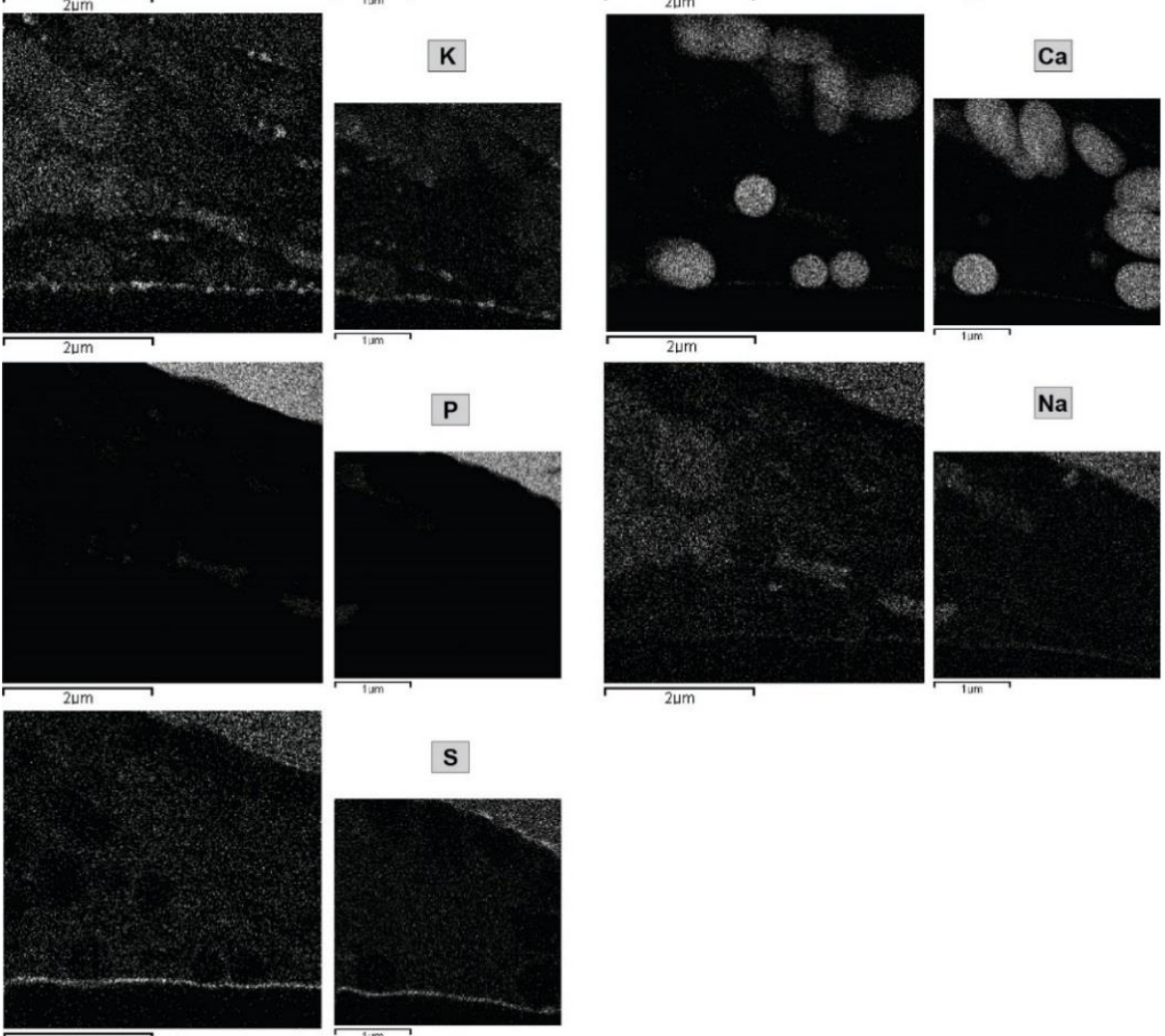

$\mathrm{Na}$

s
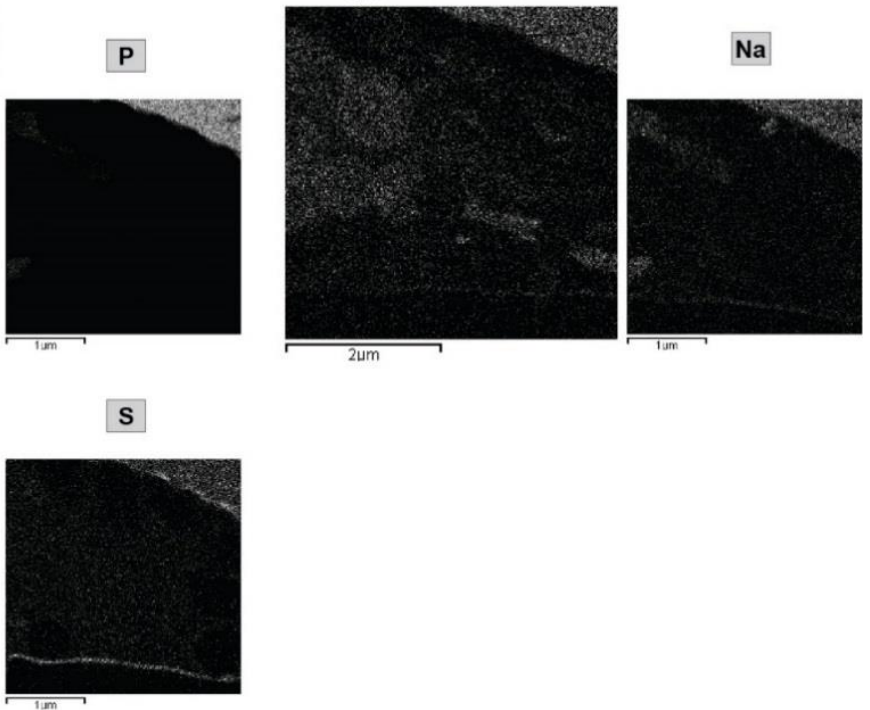

2um $2 u m$

Figure S5: TEM-EDXS mapping results performed on a FIB-cut section through a Tetraselmis contracta cell (dried culture sample). 
Top image shows the location of the two mappings on a TEM-HAADF image of the section. The maps show the concentration of the different elements: the lighter the color, the more the element is concentrated in that point. Micropearls are mainly composed of $\mathrm{Ca}$, with small quantities of $\mathrm{K}$ (and $\mathrm{Mg}$, not shown here). The ACC appears to contain less carbon than the surrounding organic matter, because calcite is known to contain $12 \mathrm{wt} \%$ of carbon while the biomass contains $40-50 \%$. Note

5 that, due to the overlap between the $\mathrm{P} K$ peak and secondary $\mathrm{Pt} L$ peak, the $\mathrm{Pt}$ which was deposited on top of the sample during FIB processing is also visible in green. 


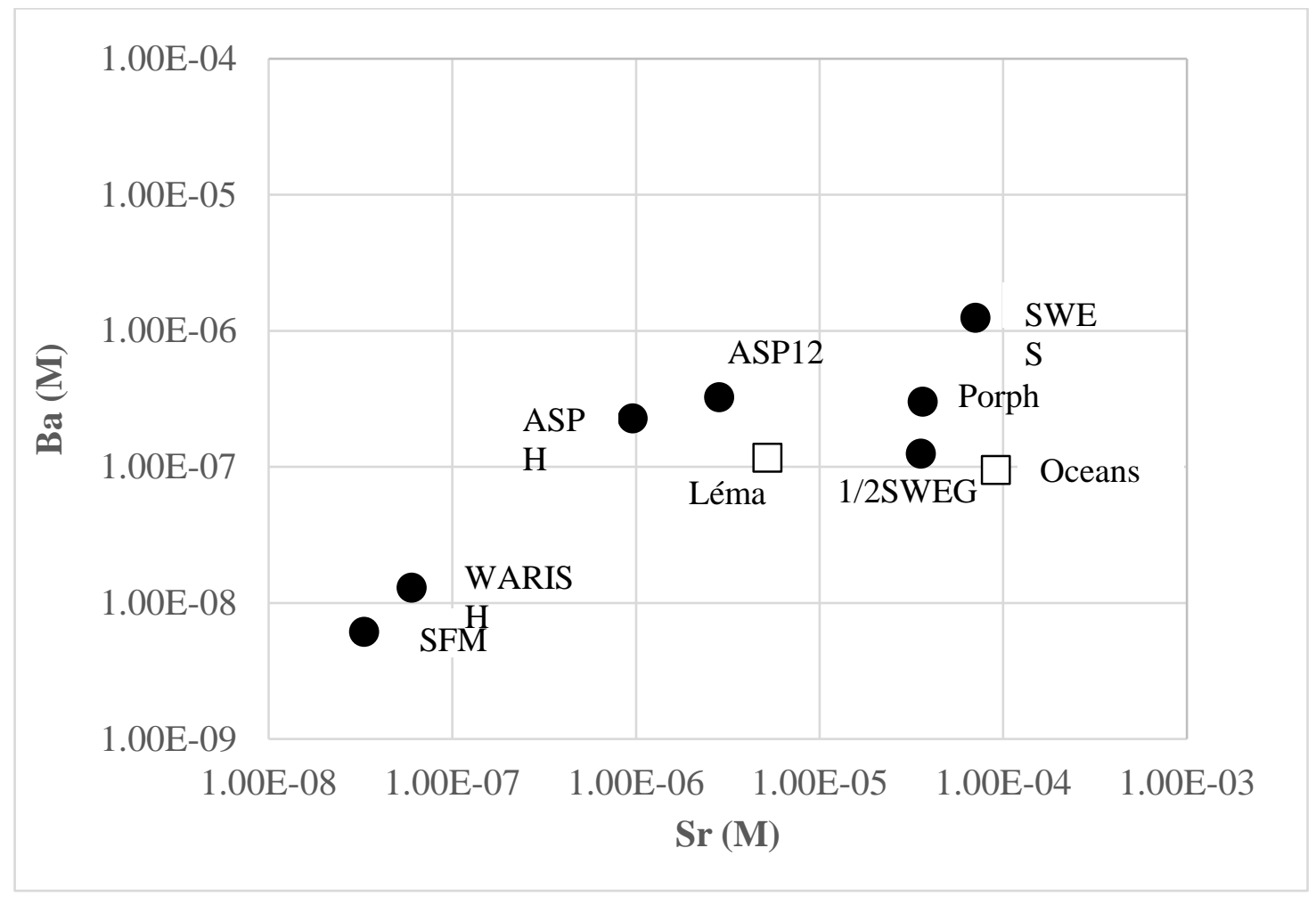

\section{Figure S6: Growth media concentrations in $\mathrm{Sr}$ and $\mathrm{Ba}$.}

Black dots: culture media; white squares: natural waters. Lake Geneva (Jaquet et al. 2013) and oceans (Bruland and Lohan, 2003). Notice the log scale.

\section{References:}

Bruland, K.W. and Lohan, M.C.: Controls of Trace Metals in Seawater, In: Treatise on Geochemistry, Volume 6. Elsevier, chapter 6.02, 2003.

Martignier, A., Pacton, M., Filella, M., Jaquet, J. M., Barja, F., Pollok, K., Langenhorst, F., Lavigne, S., Guagliardo, P., Kilburn, M. R., 15 Thomas, C., Martini, R. and Ariztegui, D.: Intracellular amorphous carbonates uncover a new biomineralization process in eukaryotes, Geobiology, 15, 240-253, doi:10.1111/gbi.12213, 2017. 


\begin{tabular}{|l|l|}
\hline Provider & Internet address \\
\hline CCAC & http://www.ccac.uni-koeln.de/sidebar/growth-media/ \\
$\begin{array}{l}\text { Culture Collection of Algae at } \\
\text { the University of Cologne }\end{array}$ & \\
\hline SAG & http://www.uni-goettingen.de/en/list+of+media+and+recipes/186449.html \\
$\begin{array}{l}\text { Sammlung von Algenkulturen at } \\
\text { the University of Göttingen }\end{array}$ & \\
\hline AC & https:/www.unicaen.fr/algobank/infos/recettes.html \\
\hline Algobank Caen University & \\
\hline
\end{tabular}

Table S1: Sources for the composition of culture media. 


$\begin{array}{ccccccc}\begin{array}{c}\text { algal } \\ \text { collection }\end{array} & \text { dilution } & \begin{array}{c}\text { Sr88(LR) } \\ {[\mathrm{ppb}]}\end{array} & \begin{array}{c}\text { Ba138(L) } \\ {[\mathrm{ppb}]}\end{array} & \begin{array}{c}\mathrm{Sr} \\ {[\mathrm{M}]}\end{array} & \begin{array}{c}\mathrm{Ba} \\ {[\mathrm{M}]}\end{array} & \mathrm{Sr} / \mathrm{Ca} \\ & & & & \end{array}$

\begin{tabular}{|c|c|c|c|c|c|c|c|}
\hline Blank - MilliQ_Ge & - & & 2,48 & 2,71 & & & \\
\hline Blank - H2O & CCAC & & 0,68 & 0,37 & & & \\
\hline Blank - MilliQ & SAG & & 23,43 & 4,14 & & & \\
\hline Temoin_10ppb & - & & 9,89 & 9,83 & & & \\
\hline Temoin_100ppb & - & & 99 & 103,06 & & & \\
\hline Waris_H & CCAC & & 5,27 & 1,77 & $6.01 \mathrm{E}-08$ & $1.29 \mathrm{E}-08$ & 1.42E-04 \\
\hline SFM & CCAC & & 2,91 & 0,84 & $3.32 \mathrm{E}-08$ & $6.12 \mathrm{E}-09$ & 1.58E-04 \\
\hline 1_2_SWEG & SAG & & 3122,6 & 17,11 & $3.56 \mathrm{E}-05$ & $1.25 \mathrm{E}-07$ & 6.77E-03 \\
\hline ASP-12 & CCAC & 100 & 249,47 & 44,42 & $2.85 \mathrm{E}-06$ & $3.23 \mathrm{E}-07$ & 2.71E-04 \\
\hline ASP-H & CCAC & 100 & 84,22 & 31,09 & $9.61 \mathrm{E}-07$ & $2.26 \mathrm{E}-07$ & $3.84 \mathrm{E}-04$ \\
\hline Porph & SAG & 100 & 3196,8 & 41,38 & $3.65 \mathrm{E}-05$ & $3.01 \mathrm{E}-07$ & 6.93E-03 \\
\hline SWES & SAG & 100 & 6201,34 & 170,84 & $7.08 \mathrm{E}-05$ & $1.24 \mathrm{E}-06$ & $6.72 \mathrm{E}-03$ \\
\hline
\end{tabular}

Table S2: Concentration of $\mathrm{Sr}$ and Ba measured in the growth media.

$\mathrm{Sr}$ and Ba: ICP-MS data.Ca concentrations were calculated based on the media theoretical composition. CCAC: Culture Collection of Algae at the University of Cologne (Germany); SAG: Sammlung von Algenkulturen of the University of 5 Göttingen (Germany); Algobank: culture collection of microalgea of the University of Caen (France). Media ES (Algobank) and Diat (SAG) were not available for analysis. 


\begin{tabular}{|c|c|c|c|c|c|c|c|c|c|c|c|c|c|c|c|}
\hline & cord-F_cc & convol_cc & contract_cc & cord-M_cc & chui_cc & cord_M_sa & cord_Gen & desika_cc & subcord_sa & chui_sa & striata_sa & tetrah & levis_ac & suecica_ac & \\
\hline Ca norm & 0.99 & 0.99 & 0.99 & 0.99 & 0.99 & 0.98 & 0.93 & 0.90 & 0.83 & 0.85 & 0.77 & 0.72 & 0.60 & 0.49 & \\
\hline Sr norm & 0.01 & 0.01 & 0.01 & 0.01 & 0.01 & 0.02 & 0.07 & 0.08 & 0.17 & 0.15 & 0.23 & 0.28 & 0.40 & 0.51 & \\
\hline & & & & & & & & & & & & & & & \\
\hline $\begin{array}{c}\mathrm{Sr} / \mathrm{Ca} \\
\mathrm{N}\end{array}$ & 48 & 22 & 23 & 68 & 48 & 21 & 70 & 22 & 42 & 31 & 38 & 33 & 29 & 33 & $\begin{array}{c}\text { Total } \\
528\end{array}$ \\
\hline Min & 0.000 & 0.000 & 0.000 & 0.000 & 0.000 & 0.000 & 0.000 & 0.000 & 0.000 & 0.013 & 0.042 & 0.161 & 0.374 & 0.490 & \\
\hline $\operatorname{Max}$ & 0.013 & 0.050 & 0.015 & 0.046 & 0.025 & 0.087 & 1.728 & 0.154 & 0.611 & 0.734 & 0.667 & 0.631 & 1.060 & 2.620 & \\
\hline Mean & 0.005 & 0.015 & 0.006 & 0.008 & 0.013 & 0.019 & 0.118 & 0.090 & 0.218 & 0.199 & 0.320 & 0.391 & 0.701 & 1.152 & \\
\hline Std. error & 0.0005 & 0.0037 & 0.0010 & 0.0008 & 0.0009 & 0.0041 & 0.0369 & 0.0096 & 0.0183 & 0.0306 & 0.0263 & 0.0181 & 0.0394 & 0.0925 & \\
\hline Stand. dev & 0.0038 & 0.0175 & 0.0046 & 0.0067 & 0.0064 & 0.0190 & 0.3090 & 0.0449 & 0.1187 & 0.1705 & 0.1618 & 0.1042 & 0.2120 & 0.5311 & \\
\hline Median & 0.005 & 0.006 & 0.006 & 0.007 & 0.013 & 0.015 & 0.025 & 0.085 & 0.208 & 0.225 & 0.290 & 0.376 & 0.661 & 1.030 & \\
\hline 25 prentil & 0.001 & 0.000 & 0.002 & 0.004 & 0.010 & 0.010 & 0.004 & 0.060 & 0.178 & 0.040 & 0.179 & 0.320 & 0.545 & 0.735 & \\
\hline 75 prentil & 0.008 & 0.030 & 0.010 & 0.011 & 0.018 & 0.024 & 0.057 & 0.133 & 0.260 & 0.290 & 0.476 & 0.469 & 0.902 & 1.465 & \\
\hline Coeff. var & 73 & 116 & 73 & 81 & 49 & 98 & 262 & 50 & 54 & 85 & 51 & 27 & 30 & 46 & \\
\hline Medium & SFM & ASP-H & ASP-H & Waris-H & ASP-H & Diat & Lake water & ASP-H & Porph Ag & 1/2 SWEg Ag & SWES Ag & Porp Ag & ES & ES & \\
\hline $\mathrm{Sr} / \mathrm{Ca}$ med & $1.58 \mathrm{E}-04$ & $3.84 \mathrm{E}-04$ & $3.84 \mathrm{E}-04$ & $1.42 \mathrm{E}-04$ & $3.84 \mathrm{E}-04$ & & $4.73 \mathrm{E}-03$ & 3.84E-04 & $6.93 \mathrm{E}-03$ & $6.77 \mathrm{E}-03$ & $6.72 \mathrm{E}-03$ & $6.93 E-03$ & & & \\
\hline $\mathrm{Sr} /$ Ca mp & $5.23 \mathrm{E}-03$ & $5.50 \mathrm{E}-03$ & $6.28 \mathrm{E}-03$ & $7.23 \mathrm{E}-03$ & $1.25 \mathrm{E}-02$ & $1.48 \mathrm{E}-02$ & $2.41 \mathrm{E}-02$ & 8.43E-02 & $2.08 \mathrm{E}-01$ & $2.25 \mathrm{E}-01$ & $2.90 \mathrm{E}-01$ & $3.76 \mathrm{E}-01$ & $6.61 \mathrm{E}-01$ & $1.03 E+00$ & \\
\hline Enrichment & 33 & 14 & 16 & 51 & 33 & & 25 & 219 & 30 & 33 & 43 & 54 & & & \\
\hline
\end{tabular}

Table S3: Composition statistics for micropearls formed by Tetraselmis species.

Composition statistics for 13 Tetraselmis strains micropearls. Values from Lake Geneva (labelled cord_Gen; Martignier et al. 2017) are given for comparison. Ca norm, Sr norm: values normalized to 1.0. In the lower part of the table, Sr/Ca ratios of the micropearls (mp) are compared to the ratios in their growth medium (med). Enrichment $=[(\mathrm{Sr} / \mathrm{Ca} \mathrm{mp}) /(\mathrm{Sr} / \mathrm{Ca}$ med $)]$.

References:

Martignier, A., Pacton, M., Filella, M., Jaquet, J. M., Barja, F., Pollok, K., Langenhorst, F., Lavigne, S., Guagliardo, P., Kilburn, M. R., Thomas, C., Martini, R. and Ariztegui, D.: Intracellular amorphous carbonates uncover a new biomineralization process in eukaryotes, Geobiology, 15, 240-253, doi:10.1111/gbi.12213, 2017. 